\title{
CULTURAS EN CONFLICTO EN LA OBRA DE CARLA LONZI
}

\section{CULTURES IN CONFLICT IN THE WORK OF CARLA LONZI}

\author{
Gemma del Olmo Campillo* \\ Universidad de Zaragoza
}

Resumen: Carla Lonzi, en su texto de 1970 Escupamos sobre Hegel, criticó de forma radical la cultura patriarcal y lo que esta había supuesto para las mujeres. A través de ella se ha justificado y defendido la subordinación de las mujeres a los hombres como algo legítimo y beneficioso. Lonzi tomó conciencia de esta situación gracias al feminismo y al grupo de Rivolta Femminile, del que formaba parte. Su apuesta política feminista irá en la línea de mostrar la inautenticidad de la cultura patriarcal que instrumentaliza las relaciones así como de plantear la necesidad de otra distinta, con valores más auténticos y libres. El conflicto de estas dos culturas queda reflejado en su obra Vai pure. Dialogo con Pietro Consagra.

Palabras clave: Feminismo radical de la diferencia, autoconciencia, autenticidad, libertad, Carla Lonzi.

*Doctora en Filosofía y docente en la Universidad de Zaragoza. Una de las líneas principales de investigación es el pensamiento y la práctica de la diferencia sexual italiana. Autora del libro: Lo divino en el lenguaje. La filosofía de Diótima en el siglo XXI, Madrid, Horas y horas, 2006. Traductora del libro de la comunidad filosófica femenina Diótima: La mágica fuerza de lo negativo, Madrid, Horas y horas, 2009. Correo electrónico: gdelolmo@unizar.es 
AвSTRACT: In her 1971 text Let's Spit on Hegel, Carla Lonzi radically criticised patriarchal culture and what it had meant for women. It has been used to justify and defent the subordination of women as something permissible and beneficial. Lonzi became aware of this situation thanks to feminism and the Rivolta Femminile group, to which she belonged. She commitment to feminist policy is designed to highlight the inauthenticity of patriarchal culture, which exploits relationships, as a way to stress the need for another culture with more authentic and freer values. The conflict between these two consciousnesses was reflected in her book Vai Pure. Dialogo con Pietro Consagra.

KEYwORDs: Radical feminism of difference, consciousness-raising, authenticity, freedom, Carla Lonzi.

\section{Introducción}

Carla Lonzi es una autora conocida fundamentalmente por su texto Escupamos sobre Hegel, escrito en verano de 1970. Un año después, en 1971, escribe La mujer clitórica y la mujer vaginal, un texto también muy citado e, igualmente, controvertido. La influencia de esta autora en el feminismo es indudable, sobre todo en el feminismo de la diferencia italiano, que en numerosos libros y artículos se declara deudor de las propuestas de Lonzi ${ }^{1}$. No obstante, a pesar de ello, llama la atención el hecho de que haya muy pocas monografías sobre su pensamiento.

Por supuesto, Lonzi suele estar presente en los volúmenes que recogen la historia del feminismo, en general, o bien del radical europeo o de la diferencia italiana, pero esto se revela insuficiente para una autora tan importante. En cualquier caso, el interés hacia su trabajo continúa, a juzgar por las últimas reediciones

1 Por no extenderme demasiado, creo que será suficiente citar tres obras relevantes de este feminismo en las que aparece Lonzi como una autora fundamental: LIBRERÍA DE MUJERES DE MILÁN (2004). No creas tener derechos. La generación de la libertad femenina en las ideas y vivencias de un grupo, Madrid: Horas y horas, pp. 29-42. DIÓTIMA (1996). Traer al mundo el mundo. Objeto y objetividad de la diferencia sexual, Barcelona: Icaria, pp. 225-233; y RIVERA GARRETAS, M.M. (2005). La diferencia sexual en la historia, Valencia: Publicacions de la Universitat de València, pp. 28-33. 
en italiano ${ }^{2}$, así como en otros idiomas ${ }^{3}$, sin olvidar, claro está, la influencia de su pensamiento ${ }^{4}$ en grupos o reflexiones actuales.

\section{Culturas en conflicto}

Su texto Escupamos sobre Hegel, como he indicado ya, es probablemente el más conocido. En él muestra un rechazo absoluto a la cultura por ser una elaboración «masculina en todos sus aspectos» (C. Lonzi, 1978, 9) que afirma y argumenta la inferioridad de la mujer. Es decir, para ella la cultura, dicha así en singular y sin ninguna precisión, es la cultura patriarcal, hecha por y para los hombres, una construcción que justifica la desigualdad entre hombres y mujeres, y que pone en peligro no solo la vida de las mujeres sino toda vida humana en general, porque su propuesta de convivencia es injusta, además de estar basada en el poder y en el miedo:

El pensamiento masculino ha ratificado el mecanismo que hace parecer necesaria la guerra, el caudillaje, el heroísmo, el abismo generacional. El inconsciente masculino es un receptáculo de sangre y de temor. Porque reconocemos que el mundo se halla habitado por estos fantasmas de muerte y vemos en la piedad el papel impuesto a la mujer, nosotras abandonamos al varón para que toque el fondo de su soledad (C. Lonzi, 1978, 46).

La cultura patriarcal, la cultura dominante, es un modo de interpretar y sentir la realidad que no solo dificulta enormemente la libertad de las mujeres sino que resulta perjudicial para la vida humana, ya que la forma de relacionarse dentro de esta cultura es la violencia y el abuso, la instrumentalización y el temor.

2 Ver LONZI, C. (2013). Sputiamo su Hegel. E altri scritti, Milán: Et al Edizioni.

- (2012). Scritti sull'arte, Milán: Et al Edizioni.

- (2011). Vai pure. Dialogo con Pietro Consagra, Milán: Et al Edizioni.

3 Ver LONZI, C. (2012). Autoportrait, JRP Ringier, 2013. Ver también, LONZI, C. (2012). "Itinerario de reflexiones». Duoda. Estudios de la diferencia sexual, 42, pp. 54-89.

4 El feminismo de Lonzi ha tenido, y continúa teniendo, una relevante influencia más allá de Italia y de Europa. En América Latina también está presente, por ejemplo en Argentina, de donde proceden las traducciones al español que se manejan hoy, y en movimientos feministas como el Feminismo radical de la diferencia del grupo chileno El Afuera <http:// es.scribd.com/doc/28768457/El-Feminismo-Radical-de-La-Diferencia-1\#scribd>, consultado el 01-03-2015.

Ver también <http://www.mujerpalabra.net/pensamiento/andreafranulic/18enunciados. htm>, consultado el 01-03-2015. 
Ni el arte, ni la religión, ni el lenguaje, ni las propuestas como el marxismo, tan influyente en aquella época, son una excepción, y tampoco hay una posible salida dentro de los partidos políticos o de propuestas ideológicas, ya que Lonzi considera que detrás de toda ideología hay una clara jerarquía de los sexos (Rivolta Femminile, en C. Lonzi, 1978, 17).

En esta cultura, por tanto, no hay lugar para una mujer libre. La fuerza del varón, dicen las mujeres del grupo de Rivolta (del que forma parte Lonzi), está en su identificación con la cultura, la de la mujer ${ }^{5}$, en la de su refutación (Rivolta Femminile, en C. Lonzi, 1978, 19). La mujer sería, en efecto, como dice Hegel, «la eterna ironía de la comunidad» (Hegel, 1978, 281), pero, a diferencia de Hegel, Lonzi no se conforma con el papel que la cultura asigna a las mujeres. Es preciso revelarse contra ese papel, contra el menosprecio hacia lo femenino. Se trata, como afirman las componentes del grupo de Rivolta, del liberarse de los estereotipos y salir de su lugar de subordinación para encontrar un espacio propio.

Las integrantes de este grupo utilizan la expresión «cultura», sin más especificaciones, no porque no haya otra sino para resaltar que esta parece ocupar todo el espacio, se presenta como única porque invisibiliza la femenina, de modo que se muestra solo una conciencia válida (la masculina), una producción pertinente (la masculina) aunque haya dos (la masculina y la femenina ${ }^{6}$ ), es decir, ponen en evidencia que en general, se actúa como si hubiera solo una, por eso hablan de la cultura, en singular y omitiendo que se trata de la patriarcal. Esta cultura está basada en el sometimiento de la mujer al hombre, acalla la conciencia femenina e impide que se manifieste.

Mi problema es entender por qué la mujer no llega al punto de subjetividad que cree una duplicidad de consciencia sobre el mundo. Siento que las consciencias son dos, que no es una, pero de hecho luego solo hay una y sin freno, como si la otra no existiera, y la otra se comporta como si no existiera de verdad (C. Lonzi, 2011, 11, traducción mía).

5 La mujer, en singular, como solía escribir Carla Lonzi.

6 Para Lonzi existen únicamente dos sexos y, salvo excepciones, sus escritos suelen referirse a las relaciones heterosexuales. Sin embargo, esto no implica que no se abra a otras posibilidades, ver MILLETTI, N. y PINTADU, I. (2012). «Il giardiniere, il giardino e le rose. L'omoerotismo in Rivolta Femminile e negli scritti di Carla Lozi», Genesis, XI/1-2, pp. 67-93. 
Lonzi solo considera válida la cultura que contemple la libertad de las mujeres; que permita el desarrollo de las dos conciencias. Para ello hay que mostrar otras propuestas de vida y de relación que posibiliten el pleno desarrollo de los seres humanos, sin discriminaciones. Una existencia basada en el cuidado y el respeto, no en la violencia y en el miedo. Quiere un universo sin respuestas ya dadas (Boccia, 1990, 77), reclama buscar las suyas propias, partir de cero, hacer una «tabula rasa».

Y aquí surgiría un problema, en cómo llegar a una "tabula rasa», y qué se puede entender por tal. En sus primeras obras feministas, me refiero a obras como Escupamos sobre Hegel y La mujer clitórica y la mujer vaginal, Lonzi subraya sobre todo la necesidad de demoler la cultura, por lo que sus acciones van en la dirección de la desculturación (C. Lonzi, 1978, 45) y de dejar a los hombres solos en su ambición. Esto, claro está, no tiene como consecuencia volver a un estado de naturaleza ni el abandono de toda cultura, algo, por lo demás, inviable. Es algo evidente, pero no está de más insistir en ello.

Este análisis tiene su origen, probablemente, en las teorías marxistas, tan influyentes en aquella época. La idea es que los cambios deben realizarse a partir de las necesidades reales de la propia vida, y esos cambios en las formas de relación, en las formas de organización social, en las normas y en la manera en que se producen los bienes, supondrían una transformación estructural que daría lugar a una cultura - una superestructura - más auténtica, nacida de necesidades vitales y no de teorías políticas o filosóficas. En Rivolta surgió una expresión que a Lonzi le gustaba mucho: «el sujeto no busca aquello que necesita sino que lo hace existir» (C. Lonzi, 2010, 31, traducción mía). Hay que hacer existir aquello que es necesario y, en el caso de las mujeres, su necesidad está en crear un mundo en el que su libertad sea pensable y posible.

La crítica radical que hacen de la cultura no es a toda cultura posible, sino a la generada por la conciencia masculina que está basada en la ocultación y menosprecio de lo femenino. No hay ningún aspecto que sea válido en ella porque toda su producción está marcada por esta condición. Es cierto, señala también, que ha habido algunos esfuerzos para huir del sistema patriarcal, y pone el ejemplo del movimiento hippie. Lonzi admite su mérito (C. Lonzi, 1978, 42), pero se muestra desilusionada porque estos movimientos no consiguen salir del sistema de referencia, puesto que reproducen los mismos estereotipos y valores viriles. 
La desilusión que el feminismo ha tenido aun con los movimientos «hippies», deriva del hecho de que el joven que no hace la guerra, sino el amor, termina por restablecer, a pesar suyo, aquel funcionamiento que lo confirma como defensor del núcleo primario del patriarcado (C. Lonzi, 1978, 112).

El rechazo de la cultura por parte de Lonzi y del grupo de Rivolta Femminile, insisto, es absoluto porque se basa en la exaltación de lo viril. Para ellas solo será una verdadera alternativa aquella cultura que reconozca la conciencia femenina y le dé el espacio que se merece. Es indudable que consideran positivo el esfuerzo por «la realización de ideales comunitarios, antirrepresivos y antiautoritarios» de los hippies, pero no es suficiente, la única manera de conseguir un cambio radical es acabar con la base que sustenta la estructura del sistema patriarcal. Es en ese sentido en el que propone hacer una tabula rasa y empezar de cero, no en el de renunciar a toda cultura.

Desde luego no es una tarea fácil, esa crítica supone en gran medida un cuestionamiento de elementos que consideramos propios o, mejor, que hemos hecho propios. Aspectos cotidianos y habituales que deben ser reinterpretados y analizados. Preguntarse por la propia cultura y distanciarse de ella es, de alguna manera, un ejercicio de autocrítica, un cuestionamiento de sí, que conlleva de manera inexorable dificultades y resistencias, pero no hay otra salida. Para Lonzi es preciso cambiar la forma en que se valora lo femenino, la consideración que tiene, el imaginario colectivo que le adjudica el papel de un ser débil e incompleto que necesita tutela y defensa. "La mujer, tal y como es, es un individuo completo. La transformación no debe producirse en ella, sino en cómo ella se ve dentro del universo y en cómo la ven otros» (C. Lonzi, 1978, 53). Esto es, su propuesta no pasa por copiar el comportamiento de los hombres, ni en relacionarse como lo hacen ellos, ni en tener sus valores.

Las mujeres no tienen que imitar a los hombres, lo que hay que hacer es empezar a valorarse a sí mismas y a las otras, además de, por supuesto, buscar su propio camino en el que ser libres, porque «ningún ser humano, ni ningún grupo, debe ser definido por referencia a otro ser humano o a otro grupo» (C. Lonzi, 1978, 25). Es hora, insiste Lonzi, de encontrar nuevas formas de relación en las que los hombres no subordinen a las mujeres, no las tutoricen ni guíen, y que tampoco les digan cómo ser libres. Ambos sexos deben encontrar el modo de relacionarse entre sí de manera respetuosa, a pesar de tener experiencias vitales muy distintas y espacios históricamente diferentes. Ambas conciencias deben encontrar la forma de expresarse libremente sin someter al otro sexo, deben 
elaborar su propia cultura, esta vez libre y auténtica, ya que se trata de no cometer los mismos errores.

En esta línea de interés por las diferencias y por iniciar un nuevo camino alternativo al que propone la cultura patriarcal, y por tanto, después de entrar en contacto con el feminismo, Lonzi intentó mantener sus relaciones de pareja con hombres de una manera más auténtica. El feminismo, afirma, supuso una transformación en ella porque le hizo tomar conciencia de todos los aspectos que quería cambiar, y sobre los que reflexionaba junto con las demás integrantes de Rivolta (C. Lonzi, 2010, 17). Concibe el feminismo como una liberación, una liberación para los hombres y para las mujeres, porque puede establecer una nueva forma de relación entre unos y otras, tanto de pareja como de amistad porque, a pesar de los estereotipos, para Lonzi «el feminismo no solo es rabia, denuncia, sino también autoconsciencia y liberación, es todo el arco, todas las fases de un proceso: el resultado es siempre el descubrimiento de sí, pero el estar en un proceso [...] modifica la civilización» (C. Lonzi, 2010, 161, traducción mía). Reitero esta idea, ella considera que el feminismo significa una liberación para las mujeres y para los hombres, una oportunidad de relacionarse de una manera más justa y respetuosa hacia las diferencias corporales y vitales que tienen un sexo y otro.

A lo largo de su vida tuvo varias relaciones de pareja pero probablemente una de las más significativas fue la que mantuvo con Pietro Consagra, desde $1963^{7}$ (C. Lonzi, 2010, 207) hasta 1980, fecha en la que rompen la relación, aunque no fue una ruptura definitiva porque volverán a encontrarse meses después y estarán juntos hasta el fallecimiento de Lonzi, en 1982. Esta ruptura está recogida en el libro Vai pure. Dialogo con Pietro Consagra, un interesante texto que en realidad es una transcripción de cuatro diálogos grabados, entre Carla Lonzi y Pietro Consagra, donde hablan de su relación. El desenlace de estos diálogos queda resumido en las dos palabras con las que termina el libro: «vai pure» (pues vete), que le da título. Tras mucho hablar, a pesar de los intentos de acercamiento, la relación no puede continuar porque, observa, son dos culturas distintas, dos formas de valorar y de priorizar. El libro concluye con el final de la relación entre ambos, de forma definitiva si nos atenemos solo al libro, pero lo cierto es que tiempo

7 Marta Lonzi y Anna Jaquinta, de manera más precisa, señalan el otoño de 1963 como fecha de inicio de la relación con Pietro Consagra, que se convierte en definitiva en 1964 . Ver LONZI, M. y JAQUINTA, A. «Biografia», en LONZI, C. (1985). Scacco ragionato. Poesie dal '58 al '63, Milán: Scritti di Rivolta Femminile, pp. 18 y 21. 
después volverán a estar juntos. Son dos formas de interpretar el mundo que en ese momento no pueden conciliarse:

Vai pure es la grabación en cuatro jornadas del momento de recapitulación de una relación en los puntos inconciliables de dos individuos que son dos culturas: la de la mujer que trata de poner las bases para su reconocimiento, y la del hombre que se refiere a la necesidad de "lo que es», que son sus necesidades (C. Lonzi, 2011, 3, traducción mía).

Aparece la afirmación aquí de que se trata de dos culturas, no es el único lugar, claro está, pero me parece significativo el hecho de que suela utilizar más la expresión de dos conciencias. Quizá esto tenga que ver con la ruptura con Consagra, o quizá no, pero es relevante que justo en el prólogo de esta obra, después de la ruptura, Lonzi hable precisamente de dos culturas, lo que nos llevaría a una apuesta más radical. La afirmación de que hay dos conciencias puede interpretarse o como dos conciencias con mayor o menor presencia y sentido dentro de una misma cultura, o bien que cada conciencia elabora su propia cultura, lo cual conlleva una mayor autonomía y, por ello, independencia entre los sexos. No voy a seguir esta línea de reflexión, pero no me resisto a insinuarla, al menos, ya que me parece muy sugerente.

La grabación, advierte la autora, no fue hecha para ser publicada, por lo que no contiene ninguna alteración motivada por decir o callar algo ante el miedo de que se vaya a hacer público. No estaba en absoluto prevista su publicación. Ella solía grabar algunas de sus conversaciones y esta era, en principio, una grabación más. La decisión de hacerla pública, con el consentimiento de Consagra (M. Lonzi y Jaquinta, en C. Lonzi, 1985, 63), fue para romper el silencio de lo que ocurre en las relaciones entre hombres y mujeres (C. Lonzi, 2011,3).

Es esta obra se puede apreciar hasta qué punto estaban unidas sus propuestas feministas y su vida (Spadaccini, 2005, 213-215), hay muchos aspectos que se pueden analizar en este sentido, aunque me gustaría detenerme sobre todo en uno: el de la autenticidad, fundamental en toda su obra (Boccia, 1990, 26) y particularmente en Vai pure, donde Lonzi reclama a Consagra una relación auténtica; ha tomado conciencia de lo que significa las relaciones inauténticas y no puede continuar en ellas. No quiere seguir viviendo dentro de la cultura patriarcal. 
Quiere autenticidad. Tanto con respecto a las relaciones como con respecto a sí, porque la conciencia solo puede desarrollarse en la autenticidad (C. Lonzi, 2011, 107). Es decir, la libertad solo será posible si hay autenticidad, la liberación solo será posible desde la honestidad consigo misma y con lo que le rodea. No hacerlo así supondría vivir en la mentira, repetir esquemas de comportamiento falsos e instrumentales que ya se han desvelado inadecuados, crueles, injustos y perniciosos. Como se puede apreciar, se trata de un punto central en su obra y en su apuesta por la reelaboración de la cultura, pero ¿qué entiende por autenticidad?

Desde luego es un término un tanto esquivo, pero la autora nos da una pista cuando seńala la existencia de dos planos: el de la autenticidad, que se desarrolla en espacios en los que el poder es negado, y el de la cultura, que está dentro del sistema de poder (C. Lonzi, 2011, 108). La autenticidad, por tanto, parece más viable en los espacios en los que el poder está ausente o casi, lugares en los que se puede desarrollar una conciencia que no esté sometida a manipulaciones y, por ello, quizá más cerca de los deseos propios. Es decir, la autenticidad y el poder, para Lonzi, no pueden coincidir, se excluyen, pues la autenticidad no puede ser impuesta. También nos da una pista al afirmar que la liberación es posible en la autenticidad (C. Lonzi, 2010, 132) y que se trata de una expresión de autonomía (C. Lonzi, 2010, 55). Es decir, la autenticidad rechaza el poder y facilita una liberación más real, sin engańos ni autoengaños, sin ficciones ni manipulaciones, en la medida de lo posible.

A mi modo de ver, la autenticidad que reclama Carla Lonzi debe entenderse sobre todo en relación con su propuesta de ruptura con la cultura masculina. Desde luego no es fácil saber bien a qué se refiere, pero creo que la clave está en la forma en la que tiene Lonzi de entender la cultura patriarcal que, afirma, se basa en la instrumentalización de las personas, es decir, en abusos y manipulaciones. Por eso para ella la construcción cultural es una prisión (C. Lonzi, 2010, 201), un lugar de dominación donde es imposible la libertad, donde predomina la inautenticidad (C. Lonzi, 2011, 51). La autenticidad solo es posible fuera de la cultura patriarcal.

En esta forma habitual de relación, instrumental y engañosa, las mujeres son las más perjudicadas, y no solo porque deben aceptar los roles de sometimiento a los que están destinadas, sino también porque se abusa de ellas. La cultura patriarcal destina determinadas tareas a las mujeres, labores importantes y básicas para la vida, pero su relevancia es ocultada, silenciada, igual que cualquiera de 
sus logros y capacidades (C. Lonzi, 2011, 44). Es decir, la cultura masculina es un conjunto de falsedades, tretas y engaños que subordinan, explotan e infantilizan a las mujeres. Hasta aquí está claro lo que quiere decir, pero Lonzi, además, señala que a esto hay que añadir que la inautenticidad dificulta la posibilidad de tomar conciencia de la situación real. Acallando e invisibilizando a las mujeres para la historia, se impide que nos percatemos del valor de su trabajo, se dificulta que la sociedad pueda reparar en la importancia de lo que han hecho y hacen, y que ellas mismas puedan darse cuenta. Hay, pues, una falta de reconocimiento de cualquier producción femenina y un exceso de reconocimiento de todo lo masculino.

Lonzi comprendió lo pernicioso que resultan ser esas ocultaciones argumentadas y autorizadas por la cultura, pues deterioran hasta lo invivible las relaciones humanas, sobre todo las que se dan entre hombres y mujeres. Por eso insiste tanto en que no quiere tener relaciones falsas, quiere eliminarlas de su vida. No quiere vivir afectos donde no se reconozca su trabajo, se huya de los problemas, se oculten las dificultades, se instale el miedo, la manipulación y la falta de valoración, y además se impida tomar conciencia de la realidad. No quiere relaciones falsas en las que no se dice la verdad por miedo o para manipular. Quiere tener lo que ella llama relaciones auténticas, relaciones honestas y sinceras basadas en la confianza y la vulnerabilidad.

Pietro Consagra no quería relacionarse de esta manera. Carla Lonzi no quería renunciar a su apuesta por relacionarse fuera de las convenciones sociales, tan dañinas para las mujeres. Ella no quería vivir lo que consideraba una vida falsa, bajo un silencio cómplice; y él no quería dejar los privilegios que le suponía esa vida. En palabras de Pietro Consagra, "a mí me pides algo que yo no te puedo dar, y yo te pido algo que tú no me puedes dar» (C. Lonzi, 2011, 129, traducción mía). Ambos intentaron entenderse pero no lo consiguieron, quizá porque se trata de dos conciencias distintas sobre el mundo (C. Lonzi, 2011, 11), que pueden coexistir sin conflicto entre ellas cuando una se anula, es decir, cuando la mujer acata y asume los papeles tradicionales reservados para ella. El problema, surge, entonces, en el momento en que las mujeres quieren mostrar su conciencia.

Para Lonzi, no supone un problema que haya dos conciencias distintas sobre el mundo, más bien considera que es una riqueza, puesto que la «relación significa conciencia recíproca y modificación consciente de sí dentro de ella» (C. Lonzi, 2011, 12, traducción mía). La existencia de otra conciencia es una riqueza que modifica de forma positiva la propia, es decir, la existencia efectiva de dos 
conciencias en el mundo es algo beneficioso. El problema y la dificultad en las relaciones entre hombres y mujeres está, precisamente, en no sentir esto como un beneficio e intentar acallar una de las dos, que suele ser la femenina, un ejercicio de poder alentado por la cultura que fomenta el sometimiento de las mujeres y la hegemonía de los hombres.

Dentro de la obra Vai pure se puede interpretar que las dos conciencias y las dos culturas de las que habla son, por una parte, la masculina, ensalzada por la cultura patriarcal y, por otra, la femenina, que es menospreciada. En realidad, como se puede apreciar en otras obras de Lonzi, esto es algo más complejo que lo que acabo de describir, puesto que hay mujeres que no han tomado conciencia de su situación y hay hombres que quieren tener otra relación con la realidad, más auténtica y menos instrumental. Probablemente, la simplificación que aparece en esta obra se debe a su procedencia: una discusión oral. Son cuatro conversaciones transcritas, lo que permite suponer que hay muchos sobreentendidos y diálogos previos que permiten simplificar. No es una obra dirigida al público, por lo que no hay matizaciones ni contextualizaciones.

En cualquier caso, teniendo en cuenta esta salvedad, lo relevante aquí es que Pietro Consagra, aparentemente, reconocía alguno de los aspectos afirmados por Lonzi: que la cultura es injusta hacia las mujeres, y que el sistema social las subordina con roles y estereotipos tradicionales abusivos hacia ellas, pero, en lugar de tomar una postura contraria a la cultura, él se quiere mantener en ella porque le favorece. No quiso renunciar a las convenciones que tanto le beneficiaban. Es decir, admitía muchos puntos comunes con respecto a las reflexiones de Lonzi (aunque no todos), pero no quería renunciar a aquello que le aportaba tanto beneficio: el arte, la cultura.

El arte, para Lonzi, forma parte de la cultura, es más, se trata de una forma de someterse a ella (C. Lonzi, 2011, 20), pero Consagra era un artista, con bastante éxito, al que le gustaban los halagos y las relaciones llenas de la afectación y falsedad características del arte, aspectos reconocidos también por el propio Consagra (C. Lonzi, 2011, 15-25). Consagra dice necesitar todo eso, la fama, la admiración, el halo especial de genio creador, para poder realizar sus obras. Sin todo eso, que sabe que es artificial, él dice no poder crear, lo necesita (C. Lonzi, 2011, 16). Le hacen falta esos elogios y exaltaciones para producir, si no los tiene no puede trabajar en sus obras, necesita ese clima de admiración, y le dice a Lonzi que le ayudaría mucho si ella formara parte de todo eso. Le dice que necesita un clima propicio para su arte (C. Lonzi, 2011, 24-25) y que a él le 
gustaría que ella hiciera lo posible por generarlo. Consagra no quiere renunciar a la cultura que tanto le aporta y elogia. Disfruta de sus privilegios, no quiere privarse de ellos, por más que sepa que puede suponer una relación injusta con las mujeres en general y con Carla Lonzi en particular.

Lonzi no puede ceder ante estas necesidades de Consagra, le resulta imposible porque una vez que ha tomado consciencia de la situación no quiere continuar en la falsedad. Para ella el feminismo y las ideas nacidas de él son mucho más que ideas, pues dice textualmente: «no es ideológico lo que digo, sino que es carnal, existencial» (C. Lonzi, 2011, 110, traducción mía). Sus ideas son parte ya de su cuerpo, no puede renunciar a ellas, una vez que se tiene autoconciencia no es posible dejar de tenerla (C. Lonzi, 2011, 85), forma parte de sí. Ya no puede volver atrás, y no quiere volver atrás; no acepta formar parte de ese mundo que rechaza a las mujeres y las instrumentaliza, que promueve relaciones falsas. Una vez que ha visto lo nefasto que es la inautenticidad, el daño que hace la cultura a las mujeres, ni quiere ni puede volver a la situación anterior a la toma de conciencia.

Quizá por eso le resulta tan difícil entender el motivo por el que Consagra la deja sola en el nuevo camino emprendido. Si en las conversaciones anteriores con él, él parecía haber entendido la situación en la que estaban las mujeres, ¿por qué no hace nada para ayudar a cambiar las cosas? Para Lonzi, la vida de las mujeres es casi invivible (C. Lonzi, 2011, 30) y es urgente cambiar esta situación. ¿Por qué Consagra quiere seguir aprovechándose de sus privilegios de hombre artista sin que ello le suponga un problema o una contradicción? Lonzi considera que es una traición (C. Lonzi, 2011, 10), le ha dejado sola en su propuesta vital de desarrollar la libertad y existencia de dos conciencias. Lo que supone ofrecer una mejora para hombres y para mujeres, sin el menosprecio ni exclusión de ningún sexo. Una posibilidad de elaborar y transitar dos culturas nuevas, alejadas de viejos e injustos esquemas, de iniciar un camino de libertad y autenticidad.

Consagra parece aceptar alguna de las críticas de Lonzi a la cultura y ser consciente de la falsedad de las relaciones al afirmar que «en el mundo masculino existe la clásica relación de defensas y ofensas, agresividad, astucias» (C. Lonzi, 2011, 91, traducción mía) pero, sin embargo, también llega a decir que las mujeres saben que los hombres viven en la especulación y en la mentira y que, de alguna manera, las mujeres esperan, y les gustan, dichos engaños (C. Lonzi, 2011, 61). Es más, considera que si ambos (Lonzi y él) siguieran los roles tradicionales, serían felices (C. Lonzi, 2011, 128). Es decir, por un lado, parece 
estar de acuerdo con la idea de que en el mundo masculino las relaciones están completamente mediadas por el poder y son siempre violentas, instrumentales y ambiciosas, pero por otro lado señala que esta elaboración masculina a las mujeres en el fondo les seduce, y que no están tan mal porque permiten una convivencia.

Sea como sea, a Lonzi no le gusta que Consagra saque provecho de una situación que ella considera en el «límite de lo invivible» (C. Lonzi, 2011, 30, traducción mía) para las mujeres, y tampoco le parece bien que opte por las relaciones falsas, que tanto se dan en el mundo del arte, siendo Consagra, como es, plenamente consciente de que son inauténticas y muy dañinas. Lonzi no entiende que no se rebele ante esta situación, que se niegue a rechazar una cultura que instrumentaliza a los seres humanos, a todos, pero en especial a las mujeres.

La cultura encubre la instrumentalización y subordinación de lo femenino mediante largas argumentaciones racionales que consiguen que esta situación parezca natural y con sentido. Una crítica que el feminismo ha tenido muy presente, por ejemplo Beauvoir en una entrevista de 1976 afirmó:

Al escribir El Segundo Sexo tomé conciencia, por primera vez, de que yo misma estaba llevando una vida falsa, o mejor, estaba beneficiándome de esta sociedad patriarcal sin percibirlo.

$$
[\ldots]
$$

A través de El Segundo Sexo tomé conciencia de la necesidad de lucha. Comprendí que la gran mayoría de las mujeres simplemente no tenía la posibilidad de elección que yo había tenido; que las mujeres son, de hecho, definidas y tratadas como un segundo sexo por una sociedad patriarcal, cuya estructura entraría en colapso si esos valores fuesen genuinamente destruidos. Así como para los pueblos dominados económica y políticamente, el desenvolvimiento de la revolución es muy difícil y muy lento. Primero, las mujeres tienen que tomar conciencia de la dominación. Después, tienen que creer en la propia capacidad de cambiar la situación. Aquellas que se beneficiaron de su "colaboración» tienen que comprender la naturaleza de su traición. Y finalmente, las que tienen más que perder por tomar posición, quiero decir, mujeres que, como yo, buscaban una situación confortable o una carrera exitosa, tienen que estar dispuestas a arriesgar su situación de seguridad (Gerassi, 1976). 
La cultura patriarcal, para Lonzi, manipula y obstaculiza la posibilidad de tomar conciencia de la realidad, de hacernos cargo de nuestra vida y de tener la libertad de cambiar aquello que no gusta. Sin embargo, a juzgar por la posición de Consagra en la obra a la que nos referimos, no parece suficiente con darse cuenta de la existencia de una situación injusta para querer cambiarla, sobre todo si ello supone la renuncia a privilegios. Las expectativas en este sentido son un tanto ingenuas y cercanas a un cierto intelectualismo moral. Quienes se benefician de una determinada situación ponen más resistencias a cambiarla, por eso Lonzi es consciente de que su propuesta no es una vía fácil. Es innegable que existe el miedo a salirse de lo establecido y perder el confort que proporciona la aceptación social, suele asustar el riesgo de aventurarse por caminos desconocidos, sobre todo si es alguien favorecido por alguno de los privilegios que la cultura ofrece a determinadas vidas ortodoxas o valoradas socialmente.

Así pues, hay muchas mujeres que no quieren arriesgarse y prefieren permanecer en la falsedad (C. Lonzi, 1978, 67-119), al igual que Consagra y muchos otros hombres. Pero no es el caso de Lonzi, ella sí quiere aventurarse, no quiere seguir sosteniendo una cultura que lleva a las mujeres al borde de lo invivible, no puede ya: no quiere más relaciones falsas en su vida. Considera que es posible relacionarse de otra manera muy distinta a la que determina el poder y la instrumentalización, y necesita apostar por ella.

Si esa forma de relacionarnos, tan interesada, violenta y manipuladora hace tanto dańo, probablemente pensó Lonzi, hagamos lo posible por cambiarla. En nuestras manos está mantener vínculos de otra manera, de una forma más generosa y menos ambiciosa. Una vez que somos conscientes de ello, en principio, tendríamos que ser capaces de cambiarlo, si queremos hacerlo, claro. Tendríamos que poder cambiar la cultura, puesto que es una construcción sostenida por los seres humanos, de ellos depende, por tanto, su mantenimiento o variación.

Betty Friedan, en su obra La mistica de la feminidad, aunque de una manera muy distinta, habla de los problemas de la infantilización de las mujeres, así como de las consecuencias que tiene aceptar y adecuarse a lo que dice la cultura que deben ser los deseos y la vida de las mujeres. Sus efectos son demoledores, que ella compara con un campo de prisioneros donde tanto la forma de relacionarse como lo que se puede hacer, pensar y desear está ya determinado y previsto (Friedan, 1965, 340-343), manipulado. Esto sería un ejemplo de los devastadores efectos de la cultura inauténtica. 
Si habla de autenticidad, y la busca, es porque Lonzi cree que es posible, que no es un ideal inviable. Es más, afirma haber tenido esa experiencia de autenticidad con Consagra en algún momento ${ }^{8}$, pero a partir de 1980 ya no. Es decir, es posible tener una relación de autenticidad, no es un ideal utópico imposible, es factible y realizable, ella lo ha experimentado. Por tanto, la noción de autenticidad no tiene tanto que ver con una concepción de la verdad en sentido objetivo y absoluto sino, creo yo, con el mayor alejamiento posible de las mentiras y de la instrumentalización de las personas. No resulta sencillo, en mi opinión, hacer una definición en positivo de lo que propone Lonzi, pues sus reflexiones quedan abiertas a las diversas situaciones y contextos, se trata, más bien, de un rechazo de la inautenticidad y de las relaciones falsas lo que, creo, define la relación auténtica buscada por Lonzi.

La toma de conciencia de los estragos que causan en la vida de las mujeres los engaños de la cultura empuja a Lonzi a buscar una mayor autenticidad en las relaciones, a proponer un cambio estructural tan importante que haría posible el desocultamiento de la otra cultura. Pero Consagra no considera que esto sea algo útil, es más, piensa que es un suicidio, en concreto le dice a Lonzi que con su propuesta ella se hace el haraquiri (C. Lonzi, 2011, 110). Sin embargo, Lonzi prefiere esa posibilidad que seguir el camino individualista y de abuso de poder masculino que lleva a una falta de reconocimiento hacia las mujeres (C. Lonzi, 2011, 46). Quiere relacionarse de otra manera, sin abusar de las demás personas, sin falsedades, lo que permitiría no solo una vida más reconfortante y sin engaños, sino también el reconocimiento de lo que hacen y han hecho muchas mujeres sistemáticamente acalladas por la cultura. Un ejemplo de ello es lo que ha hecho el propio Consagra con ella. Lonzi le recrimina a Consagra que mientras él en las obras de ella sí aparece de forma central, que es el lugar que ocupa en su vida, ella en las de él no. En las obras de Consagra, Lonzi apenas aparece, es como si no formara parte de su vida o de su obra, cuando, al parecer, ella le ayudó mucho en su trabajo y en sus escritos (C. Lonzi, 2011, 44-45). Eso es para ella un claro signo de la falta de autenticidad en su relación, porque el libro autobiográfico de Consagra", según escribe en Vai pure, le debe mucho a ella. En dicho libro, Consagra no muestra cuál ha sido la presencia de Lonzi en su vida, mientras que en el libro autobiográfico de Lonzi (Taci, anzi parla) sí se ve claramente lo que ha sido él en la vida de ella (C. Lonzi, 2011, 44-45).

8 En 1972, por ejemplo. Ver C. Lonzi, 2010, 70.

9 CONSAGRA, P. (1980). Vita mia, Milán: Feltrineli. 
De modo que la cultura patriarcal no solo es un muro infranqueable e impermeable a las necesidades y libertades de las mujeres sino que también invisibiliza y menosprecia sus trabajos, actividades y ocupaciones. No queda más remedio, para esta autora, que seguir un camino diferente: una vez que se ha tomado conciencia de la situación ya no cabe más adaptación. Resulta indispensable salir de la cultura que oprime, alejarse de los lugares del desprecio para generar espacios más libres y habitables. Y la mejor manera de lograrlo es, en su opinión, a través de los grupos de autoconciencia feministas.

Los grupos de autoconciencia se iniciaron en Estados Unidos hacia finales de los sesenta. Las norteamericanas utilizaban la expresión consciousness raising, pero el término de autoconscienza es de Lonzi (Librería de Mujeres de Milán, 2004, 38). Lonzi considera que estos grupos son imprescindibles para que las mujeres puedan reflexionar sobre su situación en la cultura, y los valora de esta manera porque en su caso lo fueron:

La consciencia de mí como sujeto político nace del grupo, de la realidad que ha podido recibir una experiencia colectiva no ideológica. Lograr hacer existir este tipo de grupo nos ha dado la medida de nuestra capacidad de salir fuera de las estructuras y de los esquemas masculinos, de liberarnos de su poder de opresión, de comenzar a existir por lo que somos. No es más que un paso, pero de naturaleza política. Nos ha hecho entender qué es estar juntas potenciando ser sí mismas en lugar de traicionarse, nos ha permitido vivir un sentido de lo completo que históricamente nos faltaba como criaturas perennemente gregarias (C. Lonzi en M. Lonzi, Jaquinta, Fonte y C. Lonzi, 1978, 151, traducción mía).

En opinión de Lonzi, los grupos de autoconciencia proporcionan la capacidad de salir de las estructuras y de los esquemas patriarcales, sin ellos sería mucho más difícil hacerlo. Seguirá confiando en ellos y sus posibilidades también cuando estaban desapareciendo en Estados Unidos y en el resto de Europa. Ella pensaba que eran una herramienta fundamental porque se habían mostrado enormemente ricos en sus hallazgos. Las mujeres, en esos grupos, reflexionaban sobre lo que de verdad querían y no querían en sus vidas, se esforzaban por no verse demasiado influidas por las distintas ideologías (pues ninguna se hacía eco de sus necesidades), hablaban en primera persona de las cosas que les preocupan de verdad y fueron el medio que encontraron para expresarse, para comunicar, tener la palabra y «volver común, transmitir» (C. Lonzi, 2010, 132, traducción mía). En ellos encontraron una voz y un reconocimiento que no habían tenido 
hasta ese momento. Esa fortaleza que Lonzi encontró en esos espacios le cambió la vida y ella pensaba que podía ser también la forma en que otras vidas cambiaran, se modificaran, mejoraran, porque esa era su apuesta teórica: hacer una cultura mejor, más libre y más justa, donde no haya relaciones falsas que instrumentalizan a las personas.

\section{Conclusiones}

Hablar y abandonar el silencio es esencial para que se tome conciencia de la situación. Está claro que las personas más dañadas por las falsas relaciones y por las exclusiones sociales son las que más necesitan cambiar esas formas de relación y de sociedad, así como también parece evidente que lo más difícil de conseguir es, precisamente, que las personas más privilegiadas quieran cambiar una situación que les beneficia. Para estas personas, como en el caso de Consagra, no es suficiente con tomar conciencia de la situación de desigualdad. Renunciar a los privilegios no es algo sencillo. Es decir, no es suficiente el hecho de saber que algo es injusto para intentar cambiarlo de verdad, es preciso el impulso de la necesidad vital, de la imposibilidad de seguir viviendo de esa manera, como en el caso de Lonzi. Las personas directamente afectadas y dañadas por determinadas situaciones son quienes se suelen mostrar más combativas a la hora de luchar para cambiar algo que les perjudica enormemente. No caben, ni quieren caber, en esos acuerdos o convenciones sociales que les hacen tan difícil la vida.

El silencio y la aceptación no es una salida posible para Lonzi. No en sus relaciones de amistad y mucho menos en su relación de pareja. No es aceptable la sumisión y el silencio, la ocultación y hacer como que aquí no ha pasado nada, como en la famosa frase al final de La casa de Bernarda Alba, de García Lorca: "¿Me habéis oído? ¡Silencio, silencio he dicho! ¡Silencio!» (García Lorca, 1982, 199). El silencio al que se han visto abocadas muchas mujeres y su ambiente asfixiante está magníficamente representado en esta obra. Enmudecer, acallar los propios deseos e inquietudes, silenciar la necesidad de libertad y de expresión, obedecer y "portarse bien", es lo que se espera de las mujeres, aunque con variaciones según la situación de cada una.

La forma de salir del silencio, obviamente, es tomar la palabra, expresarse, como propone Lonzi en el título de otro de sus libros más conocidos: «Taci, anzi parla», que sería algo así como "Calla, o mejor, habla», una obra en la que, por supuesto, nos narra su vida bajo el modelo de un diario, el diario de una 
feminista que una vez que ha tomado conciencia de su situación, que está convencida de sus ideas, no puede renunciar a ellas porque se han convertido en existenciales, se han hecho carne. 


\section{Bibliografía /References}

Boccia, M. L. (1990). L’io in rivolta. Vissuto e pensiero di Carla Lonzi, Milán: La Tartaruga.

- (2014). Con Carla Lonzi. La mia opera è la mia vita, Roma: Ediesse.

Chinese, M.G., Lonzi, C., Lonzi, M. y Jaquinta, A. (1977). Ė già politica, Milán: Scritti di Rivolta Femminile.

Cigarini, L. (1996). La política del deseo. La diferencia femenina se hace historia, Barcelona: Icaria.

Conte, L., Fiorino, V. y Martín, V. (ed.) (2011). Carla Lonzi: la duplice radicalità. Dalla critica militante al Femminismo di Rivolta, Florencia: Edizioni ETS.

Diotıмa (2003). Il pensiero della differenza sessuale, Milán: La Tartaruga.

— (1996). La sapienza di partire da sé, Nápoles: Liguori.

- (2002). Approfittare dell'assenza. Punti di avvistamento sulla tradizione, Nápoles: Liguori.

Friedan, B. (1965). La mistica de la feminidad, Barcelona: Sagitario.

García Lorca, F. (1982). La casa de Bernarda Alba, Madrid: Cátedra.

Gerassi, J. (1976). «Simone de Beauvoir: The Second Sex: 25 Years Later». Society 13, pp. 80-84. <https://www.marxists.org/reference/subject/ethics/de-beauvoir/1976/ interview.htm>, consultado el 01-03-2015. Traducción al español de Mariana Pessah: <http://culturacolectiva.com/entrevista-a-simone-de-beauvoir-25-anosdespues-de-el-segundo-sexo/>, consultado el 01-03-2015.

Hegel, G. W. F. Fenomenología del Espiritu, México: Fondo de Cultura Económica, 1978.

Librería de Mujeres de Milán (2004). No creas tener derechos. La generación de la libertad femenina en las ideas y vivencias de un grupo, Madrid: Horas y horas.

- (2006). La cultura patas arriba. Selección de la Revista Sottosopra (1973-1996), Madrid: Horas y horas.

LonZI, C. (1978). Escupamos sobre Hegel. Y otros escritos de Liberación femenina, Buenos Aires: La Pleyade.

— (2010). Taci, anzi parla. Diario di una femminista, vol. I (1972-1973), Milán: Et al Edizioni.

— (2011). Vai pure. Dialogo con Pietro Consagra, Milán: Et al Edizioni.

- (1985). Scacco ragionato. Poesie dal '58 al '63, Milán: Scritti di Rivolta Femminile.

— (1992). Armande sono io!, Milán: Scritti di Rivolta Femminile. 
— (2012). Scritti sull'arte, Milán: Et al Edizioni.

Lonzi, M., Jaquinta, A., Fonte, M. y Lonzi, C. (1978). La presenza dell'uomo nel femminismo, Milán: Scritti di Rivolta Femminile.

Milletti, N. y Pintadu, I. (2012). «Il giardiniere, il giardino e le rose. L’omoerotismo in Rivolta Femminile e negli scritti di Carla Lozi ", Genesis, XI/1-2, pp. 67-93.

Spadaccini, D. (2005). «Carla Lonzi», en Buttarelli, A., Muraro, L. y Rampello, L. (eds). Dos mil una mujeres que cambian Italia, Xátiva, Crec, pp. 213-215.

Enviado: 29/03/2105

Aceptado: 3/06/2015

Este trabajo se encuentra bajo una licencia de Creative Commons ReconocimientoNoComercial-SinObraDerivada 4.0

\section{(c) (i) $\Theta \Theta$}

